expounded by Shannon, has no place for the concept of meaning. Mackay devotes quite a lot of space to examining the concept of information, and does some discreet advertising on behalf of his own distinctions between metrical, selective, semantic and structural information content. Unfortunately these distinctions are usually ignored by writers on information theory, but this may be because the idea of information as "negative entropy" lends itself to mathematical development and tochnical application whero the other concepts do not. Perhaps time will redress the balance.

In discussing tho nature of moaning the author expresses himself in terms appropriate to automata with woll defined "transition probability matrices". Much of what he has to say is clear and cogent, but one may perhaps doubt whether this particular mathernatical concept is robust enough to carry such heavy philosophical burdens. Nevortheless, MacKay raisos concoptual questions which cannot be ignored, and his book will undoubtedly interest everybody who is seriously concerned with the relation between minds, brains and automata.

Chrtstopher Longuet-Higatns

\section{D'ARCY THOMPSON RIDES AGAIN}

\section{Symmetry and Function of Biological Systems at the Macromolecular Level}

Edited by Arne Engström and Bror Strandberg. (Procodings of the Eleventh Nobel Symposium held August $26-29,1968$, at Södergarn, Lidingö, in the County of Stockholm.) Pp. 436. (Interscience (Wiley): New York and London; Almqvist and Wiksell: Stockholm, October 1969.) $280 s$.

Srmmetry, it seems, is in. Possibly it is the delayed impact of the work of the past ten or so years on the structures of complex self-assembly systems, such as viruses and flagella, and the symmetry principles which govern them, that has caused the space groups of late to trip so lightly from biochemists' tongues. Symmetry, it has to be said, is a slender thread to link so diverse a set of articles as aro contained in this book, however, and frequently its relevance is lost to view. As with all such volumes, one imagines that the truo begetters are the publishers rather than the organizers. Published a year after the event, the papers fall into three categoriesthose that have in the meantime bcen published in re. putable journals (and a few that are still about to be), tho well-worn lecture review (and one or two in this volume prosent a remarkably threadbare appearance), and the ruminations of the patrician mind, which might otherwiso be denied to the hungry scientific prolctariat. At best, this last kind can justify the publication of symposium volumes. At worst, and moro often, one retains only the impression that all the elaborate and expensive machinery of international congresses and symposia is capable of generating nothing moro useful than the occasional blinding cloud of steam. I confess that I addressed myself to the Eleventh Nobel Symposium without enthusiasm. In the event I found much more than one could have hoped that was new, stimulating and even entertaining.

The substance of the book falls into six sections. The first, "Basic Views on Symmctry", is chiefly remarkable for an unaccountable two-page colour plate of the heads of "Australians and Occan People", but includes also a short, concentrated and stylish exposition by a mathematician (H. S. M. Coxetter) of "The Symmetry Properties of Helices and Concho-spirals". The second section is about "Prediction of the Conformation of Macromolecules", and contains the articles by Scheraga, Ramachandran and Liquori, without which no symposium is nowadays complete. There follows "Interaction between Subunits in Polymoric Proteins", which is an indigestible concoction of X-ray crystallography, electron microscopy and physical chemistry. The paper by Schuster and Ilgenfritz on the kinetics of haemoglobin oxygenation is one of the most substantial and interesting in the book, however, and is a good example of the impact of the Göttingen school on current thinking in molecular biology. "Symmetry and Cooperativity in Biological Membranes" shows the extent to which these have now been sucked into the vortex of allosterism. Nevertheless, however dyspeptic one's response to this prospect, and however much adrenaline, for that matter, one may reloase on encountering a quotation from Molière at the head (though everyone, of course, to his taste), it must be said that the paper by Changeux is an elegant piece of work. A nicely wrought intellectual structure, balanced on a very pin's tip of experimental fact, it is persuasive to a romarkable degreo, and whether or not the concepts turn out in the end to be valid, I do not doubt that it will have its effect on thinking in the field.

The remaining two sections of the book are on "Assembly and Structure of Viruses", which contains particularly an impressive article by Klug, and "Aspects of Macromolccular Assignments in Muscle", with a magisterial chapter by Casper and Cohen, on the nature and significance of polymorphism in protein aggregates, as the centrepicee. There is also a short appendix by Klug called "Point Groups and the Design of Aggregates", which sets out in a dozen pages the principles of symmetry and the mannor in which they apply to viruses as the archetypal subunit systerns.

There are, then, five or six articles in this volume which are not to be had elsewhere and which encapsulate some of the best achievements in molecular biology of the past few yoars. There are a good many others which are, I suppose, none the worse for having been published more than once, and only one that struck me as altogether bad and misleading. On this reckoning the book scores a good deal higher than most symposium volumes. It comes at a point in time at which some fundamental ideas incubated over many years by crystallographers, protein chemists and others have come to maturity. The finesse of modern techniques aside, it is D'Arcy Thompson and the great anatomists of the nineteenth century writ small. There are many things here which molccular biologists and their students will wish to ponder on.

\section{W. B. Gratzer}

\section{GENETICS BY COMPUTER}

\section{Computer Applications by Genetics}

Edited by Newton E. Morton. (Proceedings of a Confercnee sponsored by the University of Hawaii, and the Genetics Study Section, National Institute of General Medical Sciences.) Pp. ix +167 . (University of Hawaii Press: Honolulu, Hawaii, October 1969.) \$10.

THIs collection of papers is dedicated to Dr L. H. Snyder and is concerned with the applications of computers in genetics with a strong bias towards human population genetics. The sixteen papers cover a wide variety of topics, and the authors are acknowledged experts in each field. Some of the papers contain a description of the relovant computer prograrns. The discussion following the reading of some of the papers is included.

There are two papers on Monte Carlo simulation. One, by Levin, discusses the use of simulation in studying the effects of sampling, sclection, migration and competition on gene frequencies. Levin discusses in an appendix to his paper some approximate short-cut simulation methods without stressing how much these may reduce the value of the stochastic accuracy that is one of the great advantages of exact simulation. The other paper, by Latter, is an excellent, although perhaps over optimistic, discussion of the use of selection experiments and simulation studies to 